\title{
Magnetometer Device
}

National Cancer Institute

\section{Source}

National Cancer Institute. Magnetometer Device. NCI Thesaurus. Code C50053.

A device designed to measure the strength of a magnetic field. 